\title{
Searching for Genes Involved in Arteriosclerosis: Proteomic Analysis of Cultured Human Umbilical Vein Endothelial Cells Undergoing Replicative Senescence
}

\author{
Hiroki Kamino ${ }^{1}$, Masaharu Hiratsuka ${ }^{1,2}$, Tosifusa Toda ${ }^{5}$, Ryuichi Nishigaki ${ }^{2}$, Mitsuhiko Osaki ${ }^{3,4}$, \\ Hisao Ito ${ }^{4}$, Toshiaki Inoue ${ }^{2}$, and Mitsuo Oshimura ${ }^{3^{*}}$ \\ ${ }^{1}$ Departments of Molecular and Cell Genetics, ${ }^{2}$ Human Genome Science (Kirin Brewery), and Biomedical \\ Science, ${ }^{3}$ Regenerative Medicine and Biofunction, Graduate School of Medical Science, Tottori University, \\ Nishimachi 86, Yonago, Tottori 683-8503, Japan, ${ }^{4}$ Division of Organ Pathology, Department of Microbiology \\ and Pathology, Faculty of Medicine, Tottori University, Nishimachi 86, Yonago, Tottori 683-8503, Japan, and \\ ${ }^{5}$ Proteomics Collaboration Research Group, Tokyo Metropolitan Institute of Gerontology, 35-2 Sakaecho, \\ Itabashiku, Tokyo 173-0015, Japan
}

\begin{abstract}
$A B S T R A C T$. It is known that replicative senescence of endothelium in vivo contributes at least partially to agerelated vascular disorders such as arteriosclerosis. However, the genes involved in this process remain to be identified. In this study, we employed a proteomics-based approach to identify candidate genes using in vitro cultured human umbilical vein endothelial cells (HUVECs) as an experimental model for replicative senescence. By comparing protein spots from young and senescent HUVECs using two-dimensional electrophoresis, we identified three up-regulated proteins and five down-regulated proteins in senescent HUVECs as compared to young HUVECs, whose alteration was not observed during replicative senescence of primary human fibroblasts. Consistent results were obtained in Western blotting analysis using specific antibodies raised against some of these proteins, whereas there were no significant changes in the mRNA levels of these genes during senescence of HUVECs. Among them, cathepsin B, a protease participating in both intracellular proteolysis and extracellular matrix remodeling was observed to be dramatically up-regulated in senescent HUVECs and whose activity is known to be up-regulated in atherosclerotic lesions with senescence-associated phenotypes in vivo. Additional proteins, including cytoskeletal proteins and proteins involved in the processes of synthesis, turnover and modification of protein, were identified, whose function in endothelium was previously unsuspected. These proteins identified by a proteomics-based approach using cultured HUVECs may be involved not only in replicative senescence but also in functional alterations in vascular endothelial cells with senescence-associated phenotypes and may serve as molecular markers for these processes.
\end{abstract}

Key words: proteomics/endothelium/HUVEC/senescence/arteriosclerosis/cathepsin B

\section{Introduction}

Replicative senescence is the limited ability of primary mammalian cells to divide when cultured in vitro with alterations in cell function, morphology and gene expression. It has been widely assumed that replicative senescence of

*To whom correspondence should be addressed: Professor Mitsuo Oshimura, Department of Biomedical Science, Regenerative Medicine and Biofunction, Graduate School of Medical Science, Tottori University, Nishimachi 86, Yonago, Tottori 683-8503, Japan.

Tel: +81-(0)859-34-8260, Fax: +81-(0)859-34-8134

E-mail: oshimura@grape.med.tottori-u.ac.jp

Abbreviations: HUVEC, human umbilical vein endothelial cell; 2-DE, two-dimensional electrophoresis; SA- $\beta$-gal, senescence-associated $\beta$ galactosidase; $\mathrm{PD}$, population doublings. endothelial cells in vivo may be involved in a large variety of age-related pathogenesis including atherosclerosis, failure of cardiovascular system, diabetes, and hypertension (Cines et al., 1998). This view is further supported by the recent report that vascular endothelial cells with senescence-associated phenotypes are present in human atherosclerotic lesions, and that endothelial cell senescence induced by telomere shortening may contribute to atherogenesis (Minamino et al., 2002). Although the replicative life span of primary cells in culture does not correlate with donor age at least in human fibroblasts (Cristofalo et al., 1998), HUVEC cultures remain a powerful experimental model for a variety of aging-related studies. To date, some 
studies have been conducted to determine the alterations in the pattern of gene expression during the process of in vitro senescence of HUVECs. For example, Grillari et al. identified beta-IG-H3, IGFBP-3, PIG3, SEC13R, L28 as preferentially expressed genes in senescent HUVECs by using subtractive hybridization of mRNA from early passage and senescent HUVECs (Grillari et al., 2000). Other member of our group also identified EST clones expressed and proteins phosphorylated differentially between young and senescent HUVECs by using RT-PCR screening and SDS-PAGE followed by autoradiography of in vivo ${ }^{32} \mathrm{P}$-labelled proteins, respectively (H. Fukuda and M. Katoh, unpublished observations). However, the principal mechanisms of replicative senescence of endothelial cells are not fully understood. Thus, more data on differential expression patterns and relevant aging markers should be obtained. In this study, we used a proteomics-based technique (Toda et al., 1998; Nishigaki et al., 2002; Hiratsuka et al., 2003) for the identification of differentially-regulated proteins in senescent HUVECs. We were successful in identifying three protein spots up-regulated and five protein spots down-regulated in senescent HUVECs. Among them, cathepsin B, a lysosomal protease participating in both intracellular proteolysis and extracellular matrix remodeling, was included as a protein up-regulated in senescent HUVECs, whose activity is known to be up-regulated in atherosclerotic lesions (Chen et al., 2002). Additional proteins including cytoskeletal proteins and proteins involved in the processes of synthesis, turnover and modification of protein were also identified, whose function in endothelium was previously unsuspected. These proteins identified are the candidates for molecular markers and for the molecules involved in replicative senescence occurring in vivo and functional alterations in vascular endothelial cells with senescence-associated phenotypes. The possible function of these proteins in senescence and pathogenesis are also discussed.

\section{Materials and Methods}

\section{Cell culture}

HUVECs were obtained from KURABO (Japan) were grown in the HuMedia-EG (KURABO) medium supplemented with $2 \%$ fetal bovine serum, $10 \mathrm{ng} / \mathrm{ml} \mathrm{hEGF}, 5 \mathrm{ng} / \mathrm{ml} \mathrm{hFGF-B,} 10 \mu \mathrm{g} / \mathrm{ml}$ heparin, $50 \mathrm{mg} / \mathrm{ml}$ gentamicin, $50 \mathrm{ng} / \mathrm{ml}$ amphotericin $\mathrm{B}$, and $1 \mu \mathrm{g} /$ $\mathrm{ml}$ hydrocortisone at $37^{\circ} \mathrm{C}$ in a $5 \% \mathrm{CO}_{2}$ atmosphere. Primary human fibroblasts were isolated from human foreskin according to standard procedures and were cultured in Dulbecco's modified Eagle's medium (Invitrogen), supplemented with $10 \%$ fetal calf serum. Both cells were routinely split and were kept at less than $90 \%$ confluency. The number of population doublings (PD) that occurred prior to each passage was calculated according to the formula $\mathrm{PD}=\log 2[($ number of cells harvested)/(number of cells seeded)] and the number was scored from the date we obtained.

\section{Senescence-associated $\beta$-galactosidase (SA- $\beta$-gal) staining}

The senescent state was verified by in situ staining for SA- $\beta$-gal as described elsewhere (Dimri et al., 1995; Yawata et al., 2003). HUVECs grown on $60 \mathrm{~mm}$ dishes were washed three times with PBS and fixed with $2 \%$ formaldehyde $/ 0.2 \%$ glutaraldehyde in PBS for $5 \mathrm{~min}$ at room temperature. The cells were then washed two times and incubated with $\beta$-galactosidase staining solution $[40 \mathrm{mM}$ citric acid/sodium phosphate buffer ( $\mathrm{pH} 6.0), 5 \mathrm{mM}$ potassium ferricyanide, $5 \mathrm{mM}$ potassium ferrocyanide, $150 \mathrm{mM} \mathrm{NaCl}, 2 \mathrm{mM}$ $\mathrm{MgCl}_{2}$ and $1 \mathrm{mg} / \mathrm{ml}$ 5-bromo-4-chloro-3-indolyl- $\beta$-D-galactose] for $24 \mathrm{~h}$ at $37^{\circ} \mathrm{C}$.

\section{2-dimensional electrophoresis (2-DE) analysis and protein identification}

2-DE analysis followed by protein identification was performed as described in our previous paper (Toda et al., 1998; URL, http:// proteome.tmig.or.jp/2D/J_index.html). Briefly, young and senescent HUVECs on $100 \mathrm{~mm}$ dishes were washed three times in PBS, and harvested with a scraper. Cell pellets were suspended in four volumes of lysis buffer $(7 \mathrm{M}$ urea, $2 \mathrm{M}$ thiourea, $1.5 \%$ Triton X-100, 0.5\% CHAPS, 0.5\% pharmalyte, $10 \mathrm{mg} / \mathrm{ml} \mathrm{DTT,} 5 \mu \mathrm{g} / \mathrm{ml}$ aprotinin, $1 \mu \mathrm{g} / \mathrm{ml}$ leupeptin, $1 \mu \mathrm{g} / \mathrm{ml}$ pepstatin, and $1 \mathrm{mM}$ PMSF) and disrupted by sonication. In the first dimension of isoelectric focusing, an $18 \mu \mathrm{l}$ aliquot of protein extract was applied near the cathode wick on each $17 \mathrm{~cm}$ immobilized pH-gradient Readystrip ${ }^{\mathrm{TM}}$ gel, $\mathrm{pH} 4$ to $\mathrm{pH}$, and run using the PROTEAN IEF cell system (Bio-Rad). In the second dimension of SDS-PAGE, equilibrated Readystrip ${ }^{\mathrm{TM}}$ gels were placed on top of the PROTEAN II ready-gel 8-16\% T $\mathrm{T}^{\mathrm{TM}}$ (Bio-Rad) and were run vertically with SDS running buffer $(25 \mathrm{mM}$ Tris, $192 \mathrm{mM}$ glycine, $0.1 \%$ SDS). After electrophoresis, proteins were detected using a silver-staining reagent kit or Quick CBB staining reagent kit (Wako). Protein spots were quantified using the PDQuest 6.2 software (Bio-Rad).

Protein spots were excised by ProteomeWorks Spot Cutter (BioRad) followed by in-gel digestion with trypsin (Promega) according to manufacturer's specifications. The digested peptide was directly mixed with an equal volume of $10 \mathrm{mg} / \mathrm{ml}$ alpha-cyano-4hydroxy cinnamic acid and peptide mass spectra were obtained on an AXIMA-CFR MALDI-TOF-MASS (Shimadzu, Japan) platform. Peptide mass mapping was performed using Mascot Search (Matrix Science).

\section{RT-PCR}

Total RNA was isolated using the RNeasy kit (Qiagen), and was reverse-transcribed with the oligo (dT) 12-18 primer (Roche) by using the M-MLV Reverse Transcriptase (Invitrogen) for first-strand cDNA synthesis. PCR detection of each gene expression was performed with a part of the reaction $(1 \mu \mathrm{l})$ in a total volume of $10 \mu \mathrm{l}$ of reaction mixture containing $1 \mu \mathrm{M}$ of each primer, $0.2 \mathrm{mM}$ of each dNTP, and 0.25 unit of KOD Dash (TOYOBO). Reactions were performed using a GeneAmp 9700 PCR System (PE Applied Biosys- 
tems) and amplifications were performed with the cycle of $94^{\circ} \mathrm{C}$ for $10 \mathrm{sec}, 62^{\circ} \mathrm{C}$ (for $\beta$-actin) or $66^{\circ} \mathrm{C}$ (for others) for $2 \mathrm{sec}$, and $72^{\circ} \mathrm{C}$ for $2 \mathrm{~min}$ with the cycle number indicated in Figure 4 . The following primer pairs were used: P4HA1 (5'-GCCTGGCTCTCTGGCTATGAAA-3' and 5'-CACAGATGAAACATGGGATGAGG-3', amplified a 600-bp fragment); P4HA2 (5'-ATTTAGGGACGGGGAATCGTGT-3' and 5'-GGTCTCCCTCTGCTCCAGACAA-3', amplified a 413-bp fragment); BAT1 (5'-CAACGAGAAGAACCGGAAGCTC-3' and 5'-TCAAAGCGATCCTGCACATCAT-3', amplified a 411-bp fragment); gp96 (5'-GCGCCGTGTATTCATCACAGAC-3' and 5'-GCCCTTTTTCAGAAGTCGCTCA-3', amplified a 448-bp fragment); GDI- $\beta$ (5'-GCCCTCAAAAAGGAAACCATTG-3' and 5'-GGGTGGATGCATTCATTCTGTC-3', amplified a 342-bp fragment); cathepsin B (5'-GCGTCTCCAATAGCGAGAAGGA-3' and 5'-TGGGATGTAGCCAGGACTTGGT-3', amplified a 494-bp fragment); and $\beta$-actin (5'-CAAGAGATGGCCACGGCTGCT-3' and 5'-TCCTTCTGCATCCTGTCGGCA-3', amplified a 257-bp fragment). The PCR products were resolved by electrophoresis on a $1.5 \%$ agarose gel and the gel was stained in ethidium bromide.

\section{Western blotting}

Young and senescent HUVEC cells were collected in lysis buffer [50 mM Tris- $\mathrm{HCl}$ (pH 6.8), $25 \mathrm{mM} \mathrm{NaCl}, 0.5 \mathrm{mM}$ EDTA, $0.2 \%$ SDS, $0.1 \mathrm{M}$ DTT, and $10 \%$ glycerol]. Protein boiled in lysis buffer was subjected to $12 \%$ SDS-PAGE and blotted onto PVDF membranes (Millipore). Anti-human cathepsin B (The Binding Site;
PC049, 1:500 dilution in 3\% BSA/TBS-T) or anti-Grp94 (Stressgen; SPA-850, 1:300 dilution in 3\% BSA/TBS-T) was used as a primary antibody. As a secondary antibody for each primary antibody, the peroxidase-conjugated anti-sheep/goat immunoglobulin (The Binding Site; AP360, 1:1000 dilution in 3\% BSA/TBS-T) or anti-rat immunoglobulin (ZYMED, 1:3000 dilution in 3\% BSA/ TBS-T) was used, respectively. Signals were visualized by ECL plus $^{\mathrm{TM}}$ detection system (Amersham Pharmacia). Equal loading of lysate was confirmed by Pouceau S staining of the membrane (data not shown).

\section{Supplementary data}

2-DE protein maps obtained in this study are available at http:// www.proteome.jp/2D/index.html.

\section{Results}

\section{2-DE analysis of proteins}

HUVECs were cultured in vitro until about 45 PD, when the cells ceased to undergo cell division and began to exhibit an enlarged and flattened morphology (Fig. 1). In SA- $\beta$-gal staining, more than $90 \%$ of cells were positive at $45 \mathrm{PD}$, whereas few were positive at 5-6 PD (Fig. 1). Thus, we used HUVECs at 5-6 or 45 PD as young or senescent HUVECs, respectively, for subsequent proteomic analyses. On 2-DE gels stained with SYPRO Ruby, about 1000 protein spots

\section{HUVECS}

\section{early passage (5 PD)}

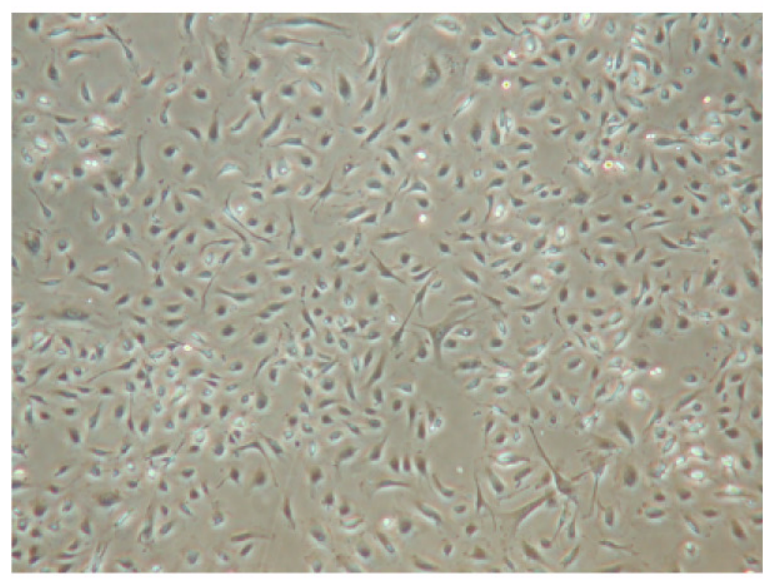

late passage (45 PD)

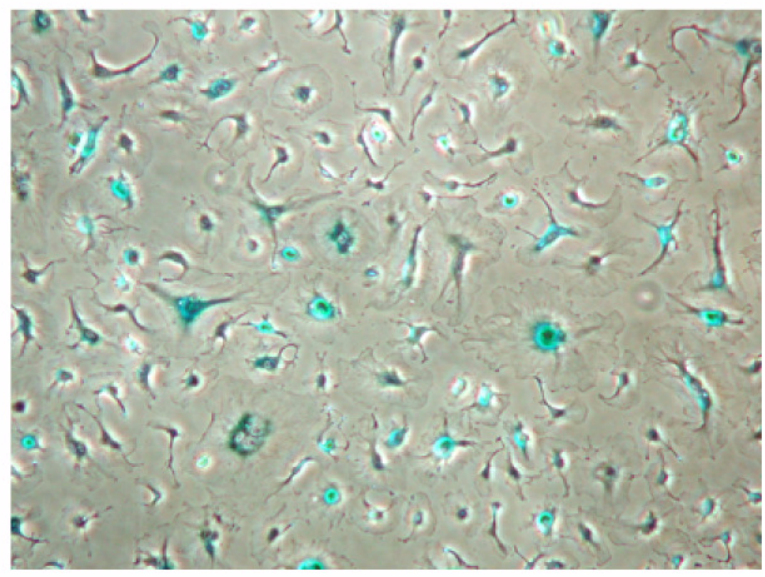

(x40)

Fig. 1. Senescent associated $\beta$-galactosidase (SA- $\beta$-gal) staining of early and late passage HUVECs. HUVECs at early passage (5 PD) and late passage (45 PD) were subject to SA- $\beta$-gal staining. Note that senescent HUVECs exhibits flattened morphology. 
were detected (Fig. 2A). The 2-DE profiles and relative spot intensities obtained from all samples were reproducible when we performed the experiments with duplicates or triplicates. Normalization was also performed using protein internal standards whose corresponding spot intensities remained unchanged between young and senescent HUVECs. In this study, only spots which had over two-fold changes in density after normalization were classified as altered (Fig. 2B). The reproducibility of data from multiple trials, the assignment of a stringent criterion for spot classification, and the use of internal protein standards ensure the reliability of the proteomic data we obtained.

As shown in Figures 2A and 2B, three up-regulated proteins and five down-regulated proteins were selected for subsequent analysis by mass spectrometry. Peptide massfingerprinting of the selected spots and subsequent database search revealed the identity of these proteins as summarized in Table I. They are composed of molecular chaperon [gp96; known as $94 \mathrm{kDa}$ glucose regulate protein (Grp94) and tumor rejection antigen (tra1)], cytoskeleton-related protein [vimentin, cytokeratin 8 , and Rho GDP dissociation inhibitor beta (Rho GDI- $\beta$ )], and proteins involved in pro-

A

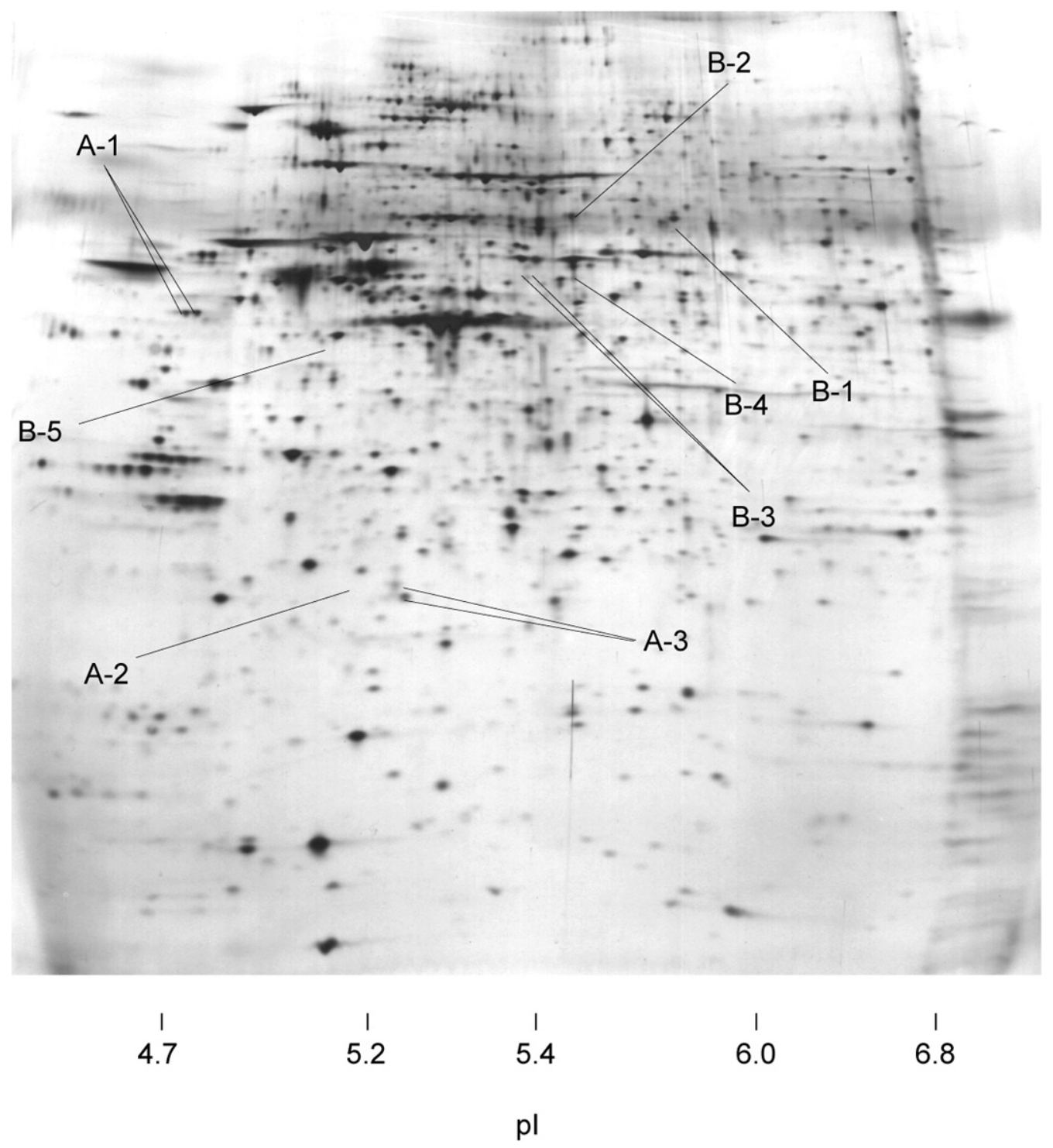

$(\mathrm{kDa})$

Fig. 2A. 
tein synthesis/modification/degradation [prolyl 4-hydroxylase alpha 1 subunit (P4HA1), prolyl 4-hydroxylase alpha 2 subunit (P4HA2), HLA-B associated transcript-1 (BAT1), and lysosomal proteinase cathepsin B]. In parallel, we performed 2-DE analyses using young (2 PD) and senescent (40 PD) primary human fibroblasts. In contrast to results obtained in HUVECs undergoing replicative senescence, the spots for vimentin, GDI- $\beta$, gp96, P4HA1, P4HA2 and cathepsin $\mathrm{B}$ were not changed during the senescence of primary human fibroblasts (Fig. 2C; data not shown), although spots corresponding to the remaining proteins were not detected, suggesting that the alterations of these proteins are specific to senescence of HUVECs, or a different set of genes may be involved in the replicative senescence between HUVECs and fibroblasts.

\section{Western blotting analysis}

We then performed Western blotting analyses to verify the reliability of the data we obtained by proteomic study. In the Western blotting to detect cathepsin B, three bands were obtained (Fig. 3). A previous report has indicated that the bands of the $31 \mathrm{kDa}$ and the $25 / 26 \mathrm{kDa}$ (doublet) correspond to the single-chain cathepsin B ( sc-CB) and the heavy

B

HUVECs

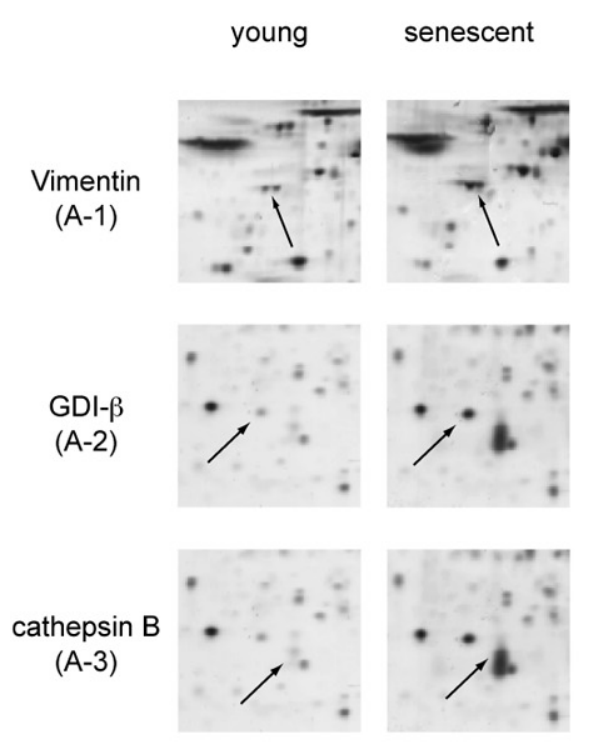

HUVECS

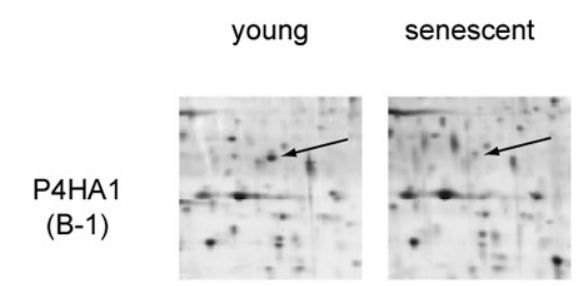

(B-1)

P4HA2

(B-2)
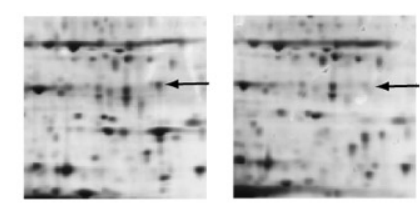

gp96

(B-5)
HUVECs

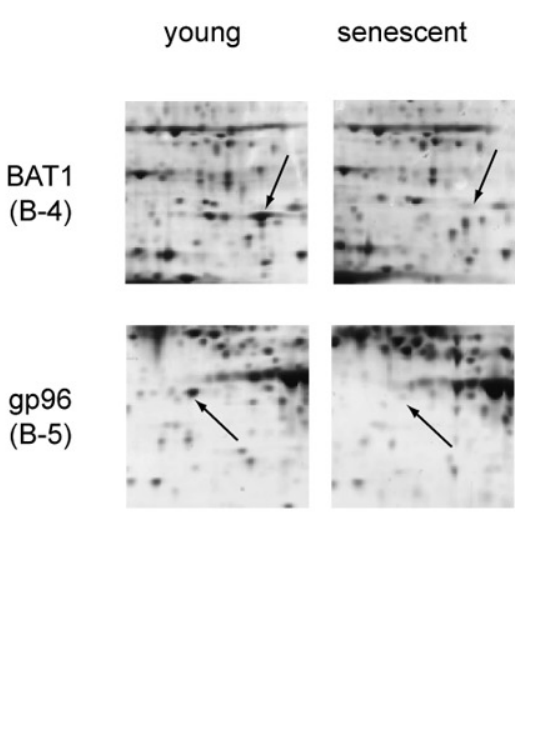

C

Primary human fibroblasts

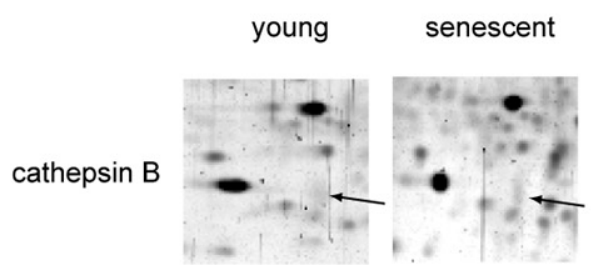

ytokeratin 8

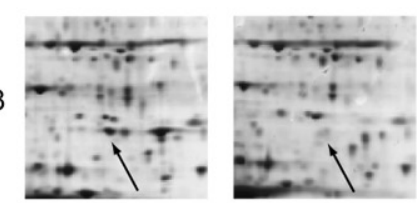

$(\mathrm{B}-3)$

Fig. 2. Two-dimensional protein profiles for HUVECs and primary human fibroblasts. (A) Patterns of protein expression in young HUVECs. Proteins were separated on the basis of $\mathrm{pI}$ (x-axis) and molecular mass (y-axis). Spots were visualized with silver staining. Numbered spots were defined as altered and then were identified by mass spectrometry. A1-A3 and B1-B5 represent up-regulated and down-regulated protein in senescent HUVECs, respectively. (B) Close-up proteins from 2-DE gels of young and senescent HUVECs. (C) 2-DE profiles of cathepsin B in primary human fibroblasts. 
Table I. List of Proteins Having Altered Expression Levels of Huvecs Undergoing Replicative Senescence

\begin{tabular}{llcccccc}
\hline Spot & Protein & $\begin{array}{c}\text { Sequence } \\
\text { Probability }\end{array}$ & Coverage $(\%)$ & $\begin{array}{c}\text { Theoretical } \\
\text { pI/kDa }\end{array}$ & $\begin{array}{c}\text { Possible } \\
\text { Function }\end{array}$ & $\begin{array}{c}\text { NCBI } \\
\text { Accession No. }\end{array}$ \\
\hline A-1 & vimentin & 258 & 54 & $4.82 / 41.7$ & cytoskeleton & gi:5030431 \\
A-2 & GDI- $\beta$ & 133 & 58 & $5.10 / 23.0$ & cytoskeleton & gi: 10835002 & 5.88 \\
A-3 & cathepsin B & 86 & 42 & $5.19 / 23.6$ & protein degradation & gi: 181178 & 25.0 \\
\hline B-1 & P4HA1 & 116 & 15 & $5.70 / 61.3$ & protein synthesis & gi: 2507090 & 0.32 \\
B-2 & P4HA2 & 94 & 27 & $5.49 / 61.3$ & protein synthesis & gi:4758868 \\
B-3 & cytokeratin 8 & 332 & 54 & $5.36 / 53.5$ & cytoskeleton & gi: 181573 \\
B-4 & BAT1 & 173 & 49 & $5.44 / 49.4$ & protein metabolism & gi: 4758112 \\
B-5 & gp96 & 108 & 19 & $4.76 / 92.7$ & molecular chaperon & gi: 4507677 & 0.08 \\
\hline
\end{tabular}

The table shows proteins that were defined as altered between young and senescent HUVECs. A1-A3 and B1-B5 represent up-regulated and down-regulated protein in senescent HUVECs, respectively.

chain of fully processed double-chain cathepsin B (dc-CB), respectively (Moin et al., 1992). The spot identified as cathepsin B is dc-CB form (data not shown), and the expression of this form of cathepsin B was significantly higher in senescent HUVECs than young HUVECs, a finding consistent with proteomic data. In primary human fibroblasts, the whole density of dc-CB was not changed between young and senescent state; however, the intensity of the lower band of dc-CB $(25 \mathrm{kDa})$ was also increased in fibroblasts in the senescent state as well in HUVECs. The same result was obtained in other batches of HUVECs (data not shown). Although the functional difference between $26 \mathrm{kDa}$ and 25 $\mathrm{kDa}$ froms of $\mathrm{dc}-\mathrm{CB}$ remains to be clarified, this raises the possibility that cathepsin $\mathrm{B}$ is involved in the replicative senescence of both HUVECs and fibroblasts although in a somewhat different fashion.

As for gp96, the spots identified as gp96 are the derivatives that appeared as bands around $50 \mathrm{kDa}$ (data not shown). These forms of gp96 were significantly down-regulated in senescent HUVECs, but a full length gp96 remained unchanged, appearing as a band at $96 \mathrm{kDa}$ was not changed (Fig. 3). In fact, all forms of gp96 remained virtually unaltered between young and senescent primary human fibroblasts (Fig. 3). These results are consistent with the data obtained in proteomic study, showing the reliability of the approach we used in this study. On the other hand, these results indicate that the regulation of protein forms may be involved in senescence.

\section{RT-PCR analysis of $m R N A$ levels}

We then performed semi-quantitative RT-PCR analyses to determine whether the changes at the protein level that were validated by $2-\mathrm{DE}$ analysis correlated with changes in mRNA levels. As shown in Figure 4, the mRNA levels of genes identified in this study were not changed significantly between young and senescent HUVECs. This suggests that the genes identified as differentially expressed at the protein level during replicative senescence may also be differentially regulated at the post-transcriptional level. This underscores the importance of a proteomics-based approach to isolate differentially regulated genes during senescence.

\section{Discussion}

In this study, we were successful in isolating three proteins up-regulated and five proteins down-regulated during replicative senescence by using a proteomics-based approach. They are composed of cytoskeleton-related proteins and proteins involved in turnover and protein synthesis. To our knowledge, this is the first report of the use of a proteomicsbased approach to HUVEC with a focus on replicative senescence.

P4HA plays a central role in the synthesis of all collagens, because the 4-hydroxyproline residues are essential for the folding of the newly synthesized collagen polypeptide chains into triple-helical molecules (Kivirikko and Myllyharju, 1998; Kivirikko and Pihlajaniemi, 1998; Myllyharju and Kivirikko, 2001). P4HAs exist as tetramers of $\alpha(\mathrm{I}) 2 \beta 2$ (Type I enzyme) or $\alpha(\mathrm{II}) 2 \beta 2$ (Type II enzyme) (Annunen et al., 1997). It has been reported that Type II functions as the main enzyme form in capillary endothelial cells, osteoblasts and chondrocytes (Annunen et al., 1998; Nissi et al., 2001). In this study, we found that prolyl 4hydroxylase $\alpha$ I and $\alpha$ II subunit were down-regulated in senescent HUVECs. This suggests that down-regulation of prolyl 4-hydroxylase may contribute to the decrease of collagen observed in aorta during senescence (Andreotti et al., 1985).

BAT1 is thought to act as a negative regulator of inflammation (Allcock et al., 2001) with properties of RNA binding activity and translation initiation factor (Peelman et al., 1995; Allcock et al., 1999). Our result that BAT1 is downregulated in senescent HUVECs raises the possibility that reduction of BAT1 in senescent endothelial cells leads to 
A

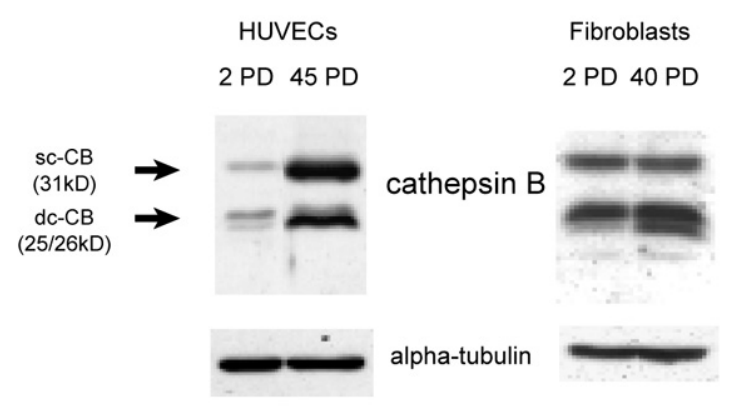

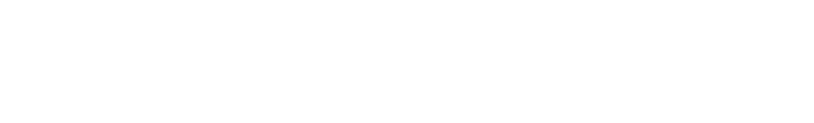

B

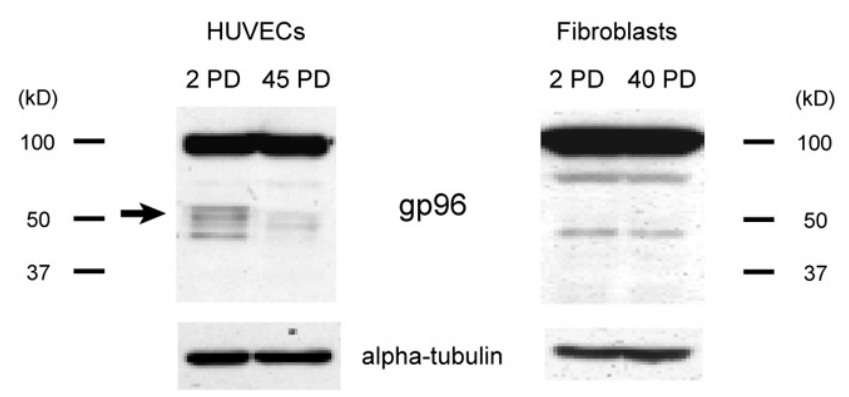

Fig. 3. Protein expression of gp96 and cathepsin B in HUVECs and primary human fibroblasts undergoing replicative senescence. HUVECs and primary human fibroblasts were harvested at young and senescent states. The cumulative PD is indicated for each sample. (A) Western blotting using anti-cathepsin B antibody. The antibody recognizes $31 \mathrm{kDa}$ singlechain cathepsin B (sc-CB) and the 25/26 kDa doublet of the heavy chain of fully processed double-chain cathepsin B (dc-CB) in both cells. (B) Western blotting using anti-gp96 antibody. This antibody recognizes the gp96 protein band of $90 \mathrm{kDa}$ in both cells. Arrow indicates differentially expressed proteins during aging in HUVECs. Their putative molecular weight is $40-60 \mathrm{kDa}$. On the other hand, differentially expression of gp96 was not observed in primary human fibroblasts.

predisposition to vascular inflammation.

gp96 is a molecular chaperon in the endoplasmic reticulum (Mazzarella and Green; 1987). It has been shown that gp96 is a high density lipoprotein-binding protein in liver (de Crom et al., 1999). Although its precise function is not clear, gp96 may contribute to control the HDL-metabolism for maintenance of normal function on vascular endothelium.

Rho GDI- $\beta$ was detected with a high level in senescent HUVECs. This protein has been to known to participate in the regulation of GDP/GTP cycle and the organization of actin cytoskeleton (Leffers et al, 1993; Gorvel et al., 1998; Olofsson, 1999; Groysman et al., 2002). In addition to Rho

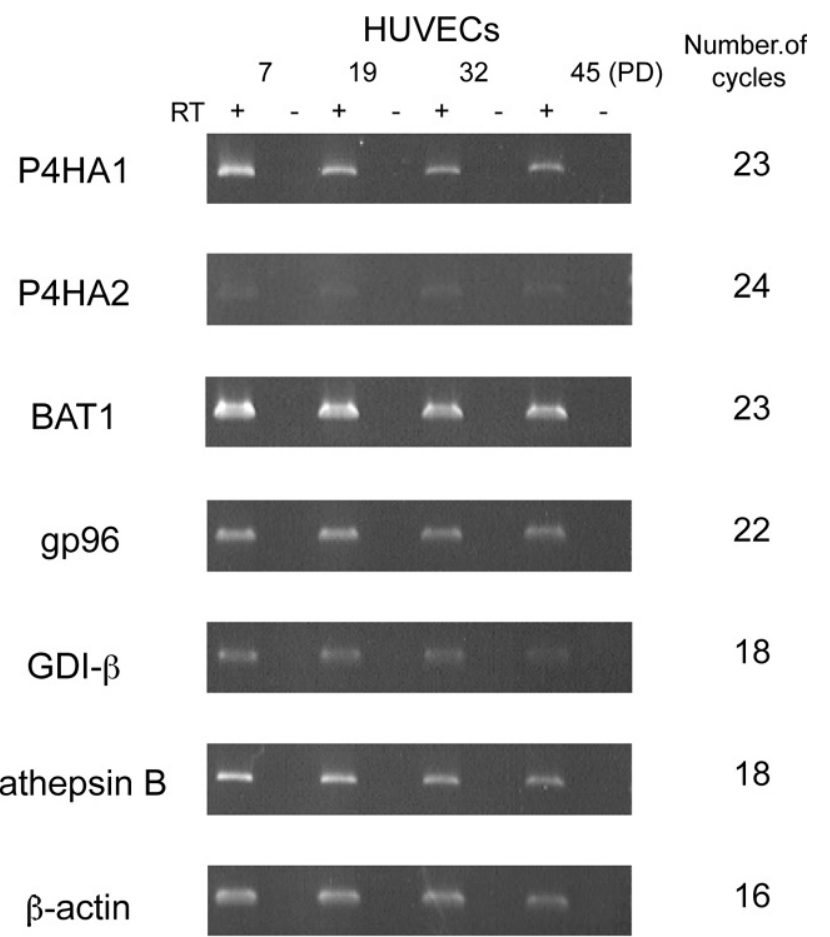

Fig. 4. Semi-quantitative RT-PCR analysis of the gene expression in HUVECs. PCR was performed for the cycle number indicated in the figure, and the products were electrophoresed on a $1.5 \%$ agarose gel, and stained with ethidium bromide. $\beta$-actin was used to guarantee that equal amounts of mRNA were used to normalize the samples.

GDI- $\beta$, we found differential expressions of vimentin and cytokeratin 8 during senescence of HUVECs. These results imply the possibility that those cytoskeletal proteins may participate in the change of cellular morphology during senescence.

It has been shown that the activity of cathepsin B, a protease participating in both intracellular proteolysis and extracellular matrix remodeling, correlates with aging and disease (Sloane, 1990; Sloane et al., 1990; Keppler et al., 2000), and that the activity of cathepsin B is up-regulated in atherosclerotic lesions in human and in aortic endothelial cells with aging in rat (Sasahara et al., 1988; Chen et al., 2002). Therefore, we regard the identification of cathepsin $B$ identified as up-regulated in senescent HUVECs, as particularly important, because this result suggests that a proteomics-based approach using cultured HUVECs may prove to be a promising system to search for genes/ proteins involved not only in in vivo replicative senescence but also aging-related pathogenesis of endothelium such as arteriosclerosis.

In the present study, we presented eight candidate proteins linked with replicative senescence of HUVECs by 2$\mathrm{DE}$ analysis. These results, particularly the identification of cathepsin B, prompted us to investigate whether the proteins identified in this study can be useful molecular markers for 
the pathogenesis of endothelium including senescence of endothelium, including failure of cardiovascular system, diabetes, and hypertension as well as atherosclerosis. Moreover, the insights of 1) no significant changes of mRNA levels of candidate genes during senescence, 2) the change of protein forms of gp96, and 3) alteration of proteins participating protein metabolism, such as cathepsin B, prolyl 4hydroxylase, and BAT1, underscore the importance of the proteomics-based approach in order to identify differentially expressed genes during senescence. In this study, we employed a HUVEC culture system as a representative experimental model of aging-related study. Therefore, it is useful to apply a proteomic approach to the human aortic endothelial as well as HUVECs to identify additional proteins differentially expressed during senescence in order to provide a more complete picture of aging markers of endothelial cells and aging-related pathogenesis in future.

Acknowledgments. We thank Y. Nakayama (Tottori University) for technical assistance with the culture of primary human fibroblasts. This work was supported in part by grants from the Ministry of Health, Labor and Welfare and the Ministry of Education, Culture, Sports, Science and Technology of Japan.

\section{References}

Allcock, R.J., Price, P., Gaudieri, S., Leelayuwat, C., Witt, C.S., and Dawkins, R.L. 1999. Characterisation of the human central MHC gene, BAT1: genomic structure and expression. Exp. Clin. Immunogenet., 16: 98-106.

Allcock, R.J., Williams, J.H., and Price, P. 2001. The central MHC gene, BAT1, may encode a protein that down-regulates cytokine production. Genes Cells, 6: 487-494.

Andreotti, L., Bussotti, A., Cammelli, D., di Giovine, F., Sampognaro, S., Sterrantino, G., Varcasia, G., and Arcangeli, P. 1985. Aortic connective tissue in ageing — a biochemical study. Angiology, 36: 872-879.

Annunen, P. Helaakoski, T., Myllyharju, J., Veijola, J., Pihlajaniemi, T., and Kivirikko, K.I. 1997. Cloning of the human prolyl 4-hydroxylase alpha subunit isoform alpha(II) and characterization of the type II enzyme tetramer. The alpha(I) and alpha(II) subunits do not form a mixed alpha(I)alpha(II)beta2 tetramer. J. Biol. Chem., 272: 1734217348.

Annunen, P., Autio-Harmainen, H., and Kivirikko, K.I. 1998. The novel type II prolyl 4-hydroxylase is the main enzyme form in chondrocytes and capillary endothelial cells, whereas the type I enzyme predominates in most cells. J. Biol. Chem., 273: 5989-5992.

Chen, J., Tung, C.H., Mahmood, U., Ntziachristos, V., Gyurko, R., Fishman, M.C., Huang, P.L., and Weissleder, R. 2002. In vivo imaging of proteolytic activity in atherosclerosis. Circulation, 105: 2766-2771.

Cines, D.B., Pollak, E.S., Buck, C.A., Loscalzo, J., Zimmerman, G.A., McEver, R.P., Pober, J.S., Wick, T.M., Konkle, B.A., Schwartz, B.S., Barnathan, E.S., McCrae, K.R., Hug, B.A., Schmidt, A.M., and Stern, D.M. 1998. Endothelial cells in physiology and in the pathophysiology of vascular disorders. Blood, 91: 3527-3561.

Cristofalo, V.J., Allen, R.G., Pignolo, R.J., Martin, B.G., and Beck, J.C. 1998. Relationship between donor age and the replicative lifespan of human cells in culture: A reevaluation. Proc. Natl. Acad. Sci. USA, 95: 10614-10619.

de Crom, R., van Haperen, R., Janssens, R., Visser, P., Willemsen, R., Grosveld, F., and van der Kamp, A. 1999. Gp96/GRP94 is a putative high density lipoprotein-binding protein in liver. Biochim. Biophys. Acta, 1437: 378-392.

Dimri, G.P., Lee, X., Basile, G., Acosta, M., Scott, G., Roskelley, C., Medrano, E.E., Linskens, M., Rubelj, I., Pereira-Smith, O, Peacocke, M., and Campisi, J. 1995. A biomarker that identifies senescent human cells in culture and in aging skin in vivo. Proc. Natl. Acad. Sci. USA, 92: 9363-9367.

Gorvel, J.P., Chang, T.C., Boretto, J., Azuma, T., and Chavrier, P. 1998. Differential properties of D4/LyGDI versus RhoGDI: phosphorylation and rho GTPase selectivity. FEBS Lett., 422: 269-273.

Grillari, J., Hohenwarter, O., Grabherr, R.M., and Katinger, H. 2000. Subtractive hybridization of mRNA from early passage and senescent endothelial cells. Exp. Gerontology, 35: 187-197.

Groysman, M., Hornstein, I., Alcover, A., and Katzav, S. 2002. Vav1 and Ly-GDI two regulators of Rho GTPases, function cooperatively as signal transducers in $\mathrm{T}$ cell antigen receptor-induced pathways. J. Biol. Chem., 277: 50121-50130.

Hiratsuka, M., Inoue, T., Toda, T., Kimura, N., Shirayoshi, Y., Kamitani, H., Watanabe, T., Ohama, E., Tahimic, C.G.T., Kurimasa, A., and Oshimura, M. 2003. Proteomics-based identification of differentiallyexpressed genes in gliomas: down regulation of SIRT2 gene in human gliomas. Biochem. Biophys. Res. Commun., 309: 558-566.

Keppler, D., Walter, R., Perez, C., and Sierra, F. 2000. Increased expression of mature cathepsin B in aging rat liver. Cell Tissue Res., 302: 181188.

Kivirikko, K.I. and Myllyharju, J. 1998. Prolyl 4-hydroxylases and their protein disulfide isomerase subunit. Matrix Biol., 16: 357-368.

Kivirikko, K.I. and Pihlajaniemi, T. 1998. Collagen hydroxylases and the protein disulfide isomerase subunit of prolyl 4-hydroxylases. Adv. Enzymol. Relat. Areas Mol. Biol., 72: 325-398.

Leffers, H., Nielsen, M.S., Andersen, A.H., Honore, B., Madsen, P., Vandekerckhove, J., and Celis, J.E. 1993. Identification of two human Rho GDP dissociation inhibitor proteins whose overexpression leads to disruption of the actin cytoskeleton. Exp. Cell Res., 209: 165-174.

Mazzarella, R.A. and Green, M. 1987. Erp99, an abundant, conserved glycoprotein of the endoplasmic reticulum, is homologous to the $90-\mathrm{kDa}$ heat shock protein (hsp90) and the $94-\mathrm{kDa}$ glucose regulated protein (GRP94). J. Biol. Chem., 262: 8875-8883.

Minamino, T., Miyauchi, H., Yoshida, T., Ishida, Y., Yoshida, H., and Komuro, I. 2002. Endothelial cell senescence in human atherosclerosis. Role of telomere in endothelial dysfunction. Circulation, 105: 15411544.

Moin, K., Day, N.A., Sameni, M., Hasnain, S., Hirama, T., and Sloane, B.F. 1992. Human tumour cathepsin B. Comparison with normal liver cathepsin B. Biochem. J., 285: 427-434.

Myllyharju, J. and Kivirikko, K.I. 2001. Collagens and collagen-related diseases. Ann. Med., 33: 7-21.

Nishigaki, R., Shinohara, T., Toda, T., Omori, A., Ichinose, S., Itoh, M., Shirayoshi, Y., Kurimasa, A., and Oshimura, M. 2002. An extra human chromosome 21 reduces mlc-2a expression in chimeric mice and down syndrome. Biochem. Biophys. Res. Commun., 295: 112-118.

Nissi, R., Autio-Harmainen, H., Marttila, P., Sormunen, R., and Kivirikko, K.I. 2001. Prolyl 4-hydroxylase isoenzymes I and II have different expression patterns in several human tissues. J. Histochem. Cytochem., 49: $1143-1153$.

Olofsson, B. 1999. Rho guanine dissociation inhibitors: pivotal molecules in cellular signalling. Cell. Signal., 11, 545-554.

Peelman, L.J., Chardon, P., Nunes, M., Renard, C., Geffrotin, C., Vaiman, M., Van Zeveren, A., Coppieters, W., van de Weghe, A., Bouquet, Y., Choy, W.W., Strominger, J.L., and Spies, T. 1995. The BAT1 gene in the MHC encodes an evolutionarily conserved putative nuclear RNA helicase of the DEAD family. Genomics, 26: 210-218.

Sasahara, M., Hazama, F., Amano, S., Hayase, Y., Yukioka, N., Kawai, J., 
Proteomic Analysis of Senescence in Endothelium

and Kataoka, H. 1988. Effect of hypertension on lysosomal enzyme activities in aortic endothelial cells. Atherosclerosis, 70: 53-62.

Sloane, B.F. 1990. Cathepsin B and cystatins: evidence for a role in cancer progression. Semin. Cancer Biol., 1: 137-152.

Sloane, B.F., Moin, K., Krepela, E., and Rozhin, J. 1990. Cathepsin B and its endogenous inhibitors: the role in tumor malignancy. Cancer Metastasis Rev., 9: 333-352.

Toda, T., Kaji, K., and Kimura, N. 1998. TMIG-2DPAGE: a new concept of two-dimensional gel protein database for research on aging. Electro- phoresis, 19: 344-348.

Yawata, T., Kamino, H., Kugoh, H., Katoh, M., Nomura, N., Oishi, M., Horikawa, I., Barrett, J.C., and Oshimura, M. 2003. Identification of a $\leq 600-\mathrm{kb}$ region on human chromosome $1 \mathrm{q} 42.3$ inducing cellular senescence. Oncogene, 22: 281-290.

(Received for publication, September 18, 2003

and accepted, November 17, 2003) 